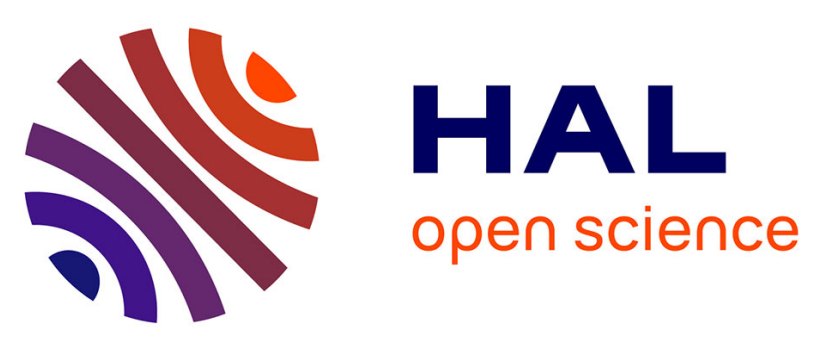

\title{
Localized CVD growth of oriented and individual carbon nanotubes from nanoscaled dots prepared by lithographic sequences
}

Bridgite Vigolo, Costel Sorin Cojocaru, Jaques Faerber, J. Arabski, Laurent Gangloff, Pierre Legagneux, Henry Lezec, Francois Le Normand

\section{To cite this version:}

Bridgite Vigolo, Costel Sorin Cojocaru, Jaques Faerber, J. Arabski, Laurent Gangloff, et al.. Localized CVD growth of oriented and individual carbon nanotubes from nanoscaled dots prepared by lithographic sequences. Nanotechnology, 2008, 19, pp.135601. 10.1088/0957-4484/19/13/135601 . hal-00796268

\section{HAL Id: hal-00796268 \\ https://hal.science/hal-00796268}

Submitted on 2 Mar 2013

HAL is a multi-disciplinary open access archive for the deposit and dissemination of scientific research documents, whether they are published or not. The documents may come from teaching and research institutions in France or abroad, or from public or private research centers.
L'archive ouverte pluridisciplinaire HAL, est destinée au dépôt et à la diffusion de documents scientifiques de niveau recherche, publiés ou non, émanant des établissements d'enseignement et de recherche français ou étrangers, des laboratoires publics ou privés. 


\title{
Localized CVD growth of oriented and individual carbon nanotubes from nanoscaled dots prepared by lithographic sequences
}

\author{
B Vigolo ${ }^{1,4}$, C S Cojocaru ${ }^{1,5}$, J Faerber ${ }^{1}$, J Arabski ${ }^{1}$, L Gangloff ${ }^{2}$, \\ P Legagneu $^{2}, H_{\text {Lezec }}{ }^{3,6}$ and F Le Normand ${ }^{1,}$ \\ ${ }^{1}$ Institut de Physique et Chimie des Matériaux de Strasbourg, UMR 7504 Centre National de \\ la Recherche Scientifique (CNRS)-Université Louis Pasteur (ULP), \\ 23 rue du Loess, BP 43, F-67034 Strasbourg Cedex 2, France \\ 2 Thales Research and Technology, Domaine de Corbeville, F-91404 Orsay Cedex, France \\ 3 Institut de Sciences et d'Ingénierie Supramoléculaires-Laboratoire des Nanosciences (ISIS), \\ UMR 7006 Centre National de la Recherche Scientifique (CNRS)-Université Louis Pasteur \\ (ULP), 8 allée Gaspard Monge, F-67083 Strasbourg, France \\ 4 Present address: Laboratoire de Chimie du Solide Minéral, UMR 7555 \\ Centre Nationale de la Recherche Scientifique (CNRS)-Université Henri \\ Poincaré (UHP), BP 239, F-54506 Vandoeuvre-lès-Nancy, France. \\ 5 Laboratoire Physique des Interfaces Couche Minces, (LPICM), UMR 7647 Centre Nationale de la Recherche Scientifique (CNRS)-École \\ Polytechnique, Route de Saclay, 91128 PALAISEAU Cedex, France. \\ 6 Present address: Thomas J Watson, Sr. Laboratories of Applied Physics, California Institute of Technology, MC 128-95, Pasadena, CA 91125, USA
}

\begin{abstract}
Using a combination of top-down lithographic techniques, isolated, individual and oriented multi-wall carbon nanotubes (MWNTs) were grown on nickel or iron nanoscaled dots. In the first step of the process, micron-sized catalytic metallic dots (either iron or nickel) were prepared using UV lithography. MWNTs were then synthesized from these catalysts using a direct current plasma-assistance and hot-filament-enhanced chemical vapor deposition (CVD) reactor. Samples were characterized by means of scanning electron microscopy. It turns out that the splitting up of the micron-sized dot is favored in the iron case and that the surface diffusion of the metal is enhanced using ammonia in the gaseous mixture during the CVD process. The results are discussed giving arguments for the understanding of the MWNT growth mechanism. In a second step, a focused ion beam (FIB) procedure is carried out in order to reduce the initial dot size down to submicronic scale and subsequently to grow one single MWNT per dot. It is found that nickel is most appropriate to control the size of the dot. Dots of size $200 \mathrm{~nm} \pm 40 \mathrm{~nm}$ are then required to grow individual MWNTs.
\end{abstract}

\section{Introduction}

Carbon nanotubes are universally recognized to have high potential for applications in many fields [1]. Their nanometer scale size, high aspect ratio and high specific surface area combined with their remarkable electrical and mechanical properties make them an ideal object for their insertion in high performance devices. The fabrication of nanotube-based prearranged structures constitutes a required first step for their utilization to manufacture electronic and field-emission devices, scanning probes or novel nanoscale tools [2-5]. The possibility to directly grow one individual and oriented carbon nanotube exactly at the desired location can help in their insertion in various assembled systems [6]. However, the handling and the positioning of these nano-objects require heavy set-up and tedious manipulation [7]. Catalytic CVD and related techniques offer the possibility to grow nanotubes directly onto the desired substrate. During the catalytic 
process, gaseous molecules $\left(\mathrm{C}_{2} \mathrm{H}_{2}, \mathrm{CH}_{4} \ldots\right)$ decompose on the surface of the metallic particles and the released carbon diffuses from the top of the particles to lead to the formation of graphitic sheets, forming carbon nanotubes by wrapping [8]. It was persistently observed that the diameter and the density of carbon nanotubes are directly correlated with the nature, size and density of the catalytic particles [9-12]. This is the reason why the control of the structuring of the catalytic nanoparticles, giving the key to having better control of carbon nanotube characteristics, represents a major challenge. Without patterning of the catalytic surface, the CCVD asproduced carbon nanotubes usually form well-known highdensity carpets, from where MWNTs are difficult to separate and isolate due to some bundling on top of it. Plasma-enhanced CCVD processes offer good opportunities to produce highly aligned and individual carbon nanotubes [13-19]. The carbon nanotubes are then aligned along the electric field created by the plasma process. Owing the geometry of the set-up, they grow generally in the direction normal to the substrate.

In this paper, we report on the preparation of patterned substrates using lithographic steps in order to grow individual and oriented carbon nanotubes at the desired location. The catalyst-supported CVD technique used for nanotube growth is activated with both hot filaments and direct current plasma (DC HF CCVD process). Ultraviolet lithography techniques and a focused ion beam (FIB) etching procedure were subsequently carried out in order to diminish step by step the catalyst particle size. Micron-sized catalytic dots are first obtained using UV lithography. The FIB lithography technique, in a second step, offers the accuracy required to structure the catalyst in the nanometer scale range. As catalysts, iron and nickel are investigated on $\mathrm{SiO}_{2} / \mathrm{Si}(100)$ substrates. We have observed that the catalyst structuring on the oxide surface (resulting from breaking up of the micron-sized initial dot and diffusion of the smaller dots produced) strongly depends on the gas mixture, as shown by adding ammonia to the gas vector during the growth process. For both catalysts, it turns out that carbon nanotube synthesis results from a top-growth mechanism. In contrast, the comparison between the two metals reveals a divergent behavior especially regarding the splitting up of the micron-sized dot and accordingly the density and the diameter of the grown carbon nanotubes. Whereas iron micron-sized dots have a high tendency to split up into very small particles and disperse under the ion beam, the size of nickel dots is well controllable using FIB lithography down to ten nanometers. We have found that nickel particles having a diameter of $200 \mathrm{~nm} \pm 40 \mathrm{~nm}$ are then required to grow an individual MWNT per dot.

\section{Experimental details}

\subsection{Lithography}

The substrate consisted of a wafer of silicon (100) coated by a silicon oxide $\left(\mathrm{SiO}_{2}\right)$ layer deposited using an electron cyclotron resonance (ECR) plasma. The role of the $\mathrm{SiO}_{2}$ layer was to prevent metal diffusion across the silicon and to avoid the formation of metallic silicides, which compete with the catalyst to grow MWNTs. The thickness of the oxide layer was chosen as thin as $10 \mathrm{~nm}$ to guarantee the electronic conduction of the sample. The lithographic sequences which were carried out to define the catalyst areas are detailed in scheme 1.

The initial $\mathrm{Si}(100) / \mathrm{SiO}_{2}$ substrate was spin-coated by two layers of a UV-sensitive polymer: copolymer polymethyl methacrylate/methacrylic acid (PMMA(8.5)MAA) and polymethyl methacrylate (PMMA), successively (step 1). After the UV beam exposure and development, an array of micron-sized holes was patterned (step 2). The cap shape of the hole, guaranteeing the control of the metal dot size, was obtained by means of the first photoresist layer PMMA(8.5)MAA being more UV-sensitive than the upper one. A 5-7 nm thick metal film (nickel or iron) was then evaporated at room temperature using a molecular beam epitaxy (MBE) technique (step 3). Acetone was used as the solvent to lift off the polymer and to develop an array of metallic dots which possess a diameter in the micron scale range (step 4). At this step, the patterned substrate was either directly introduced inside the synthesis chamber for carbon nanotube growth or the micron-sized dots were etched using FIB in order to further reduce their size (step 5).

Regarding the FIB etching stage, the flux intensity and the exposure time of the gallium ion beam $\left(\mathrm{Ga}^{+}\right)$were optimized for each metal. An intensity of several tens of pA was finally chosen to keep a good resolution and to have a certain extent of freedom to modify the exposure time. The shape of the ion beam etching pattern was a corona having an external diameter much larger than the UV-dot one $(\sim 2 \mu \mathrm{m})$, the internal diameter fixing the diameter of the final catalyst particle. Dots were etched one by one to obtain the desired diameter within a 20-240 nm range. To ensure good reproducibility, a minimum of three dots with the same diameter were prepared while keeping the same lithographic conditions.

\subsection{Nanotube growth}

The lithographed substrates were transferred inside the synthesis chamber of the DC HF CCVD reactor. The geometry of the reactor was especially studied to guide the activated species perpendicular to the substrate surface and to induce the alignment of the produced carbon nanotubes. It has been previously shown that this DC HF CCVD technique, described in detail elsewhere [20], leads to the formation of aligned and well-defined MWNTs [21, 22]. The sample was first annealed under vacuum and, at around $400{ }^{\circ} \mathrm{C}$, was submitted to hydrogen plasma for one minute to reduce the oxidized metal on the surface. The MWNT growth was performed at $700{ }^{\circ} \mathrm{C}$. The gaseous mixture $\left(20 \%\right.$ acetylene $\left(\mathrm{C}_{2} \mathrm{H}_{2}\right)$, either diluted in pure $\mathrm{H}_{2}$ or in a mixture of $\mathrm{H}_{2}$ and a small amount of ammonia (1 or $3 \%)$ ), was introduced into the chamber by a mass flow controller and the pressure was stabilized at 15 mbar. The MWNT synthesis was activated with filaments heated at $1900{ }^{\circ} \mathrm{C}$ and the dc plasma was in the meantime stabilized in between two electrode grids. The deposition was carried out for the chosen time in a stable extraction plasma. For each sample, the two experimental parameters allowed to vary were the growth time and the $\mathrm{NH}_{3}$ concentration in $\mathrm{H}_{2}$. They have been recalled in the second part of table 1. 


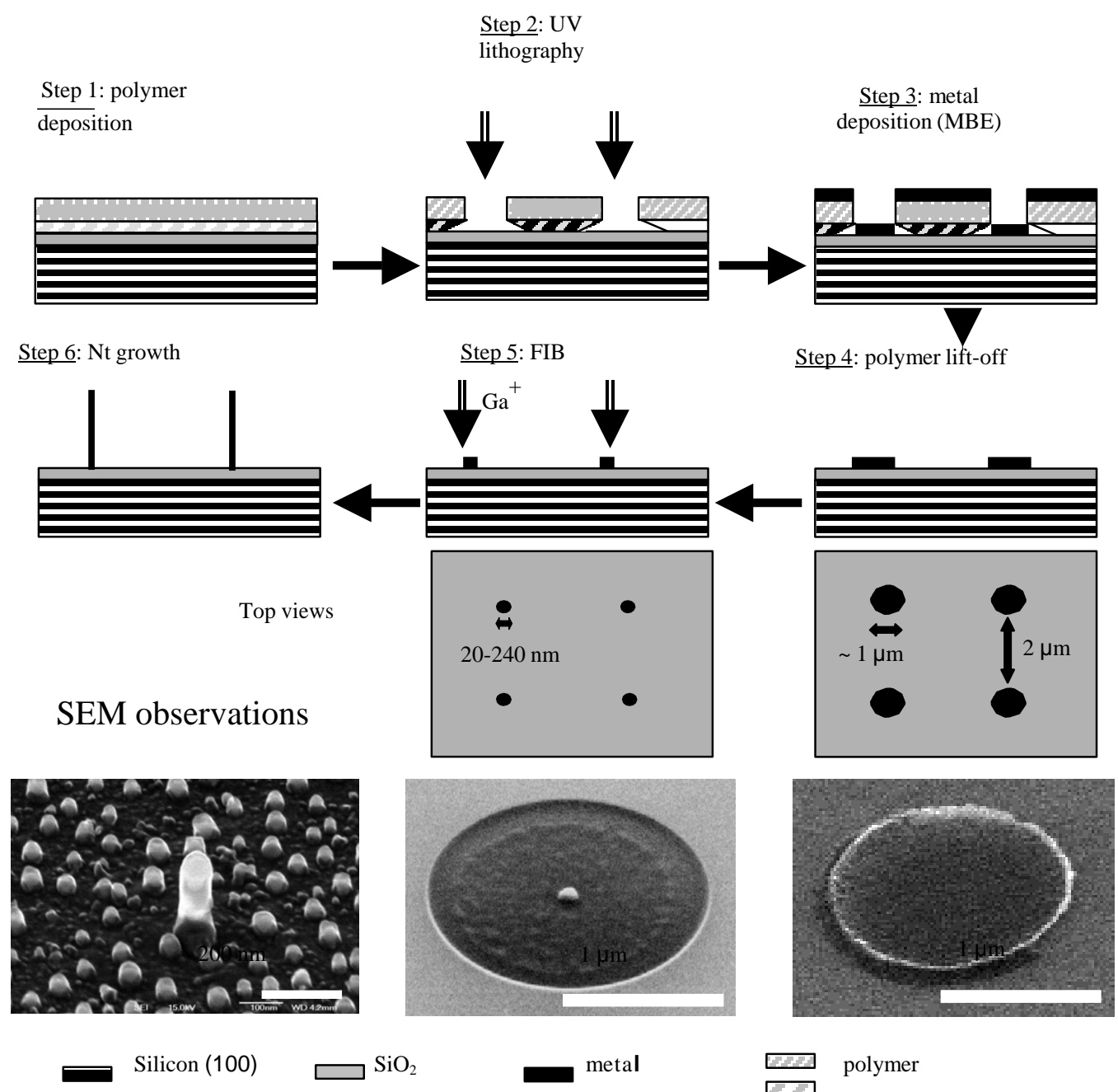

Scheme 1. Schematic view of the lithographic sequences performed in order to structure an array of catalytic dots. Steps 4,5 and 6 are illustrated with SEM micrographs of an individual dot.

Table 1. Experimental conditions for the catalytic dot preparation, carbon nanotube growth and carbon nanotube properties from SEM observations.

\begin{tabular}{|c|c|c|c|c|c|}
\hline \multicolumn{2}{|c|}{ Sample } & \multirow{2}{*}{$\begin{array}{l}\mathrm{A} \\
\mathrm{Fe}\end{array}$} & \multirow{2}{*}{$\begin{array}{l}\mathrm{B} \\
\mathrm{Ni}\end{array}$} & \multirow{2}{*}{$\begin{array}{l}\mathrm{C} \\
\mathrm{Ni}\end{array}$} & \multirow{2}{*}{$\begin{array}{l}\mathrm{D} \\
\mathrm{Ni}\end{array}$} \\
\hline Substrate preparation & Catalyst & & & & \\
\hline & Dot diameter (nm) & 1500 & 1800 & 1800 & 1800 \\
\hline & Dot thickness (nm) & 5 & 7 & 7 & \\
\hline \multirow[t]{2}{*}{ DC HF CCVD growth parameters } & Growth time (min) & 15 & 30 & 15 & 15 \\
\hline & $\mathrm{NH}_{3}(\%)$ in $\mathrm{H}_{2}$ & 0 & 0 & 1 & 3 \\
\hline \multirow[t]{6}{*}{ MWNT characteristics } & Mean diameter (nm) & 20 & 84 & 110 & 110 \\
\hline & Mean length (nm) & 400 & 520 & 330 & 680 \\
\hline & Growth rate $\left(\mathrm{nm} \min ^{-1}\right)$ & 27 & 17 & 22 & 45 \\
\hline & Density (CNTs $\mu \mathrm{m}^{-2}$ ) & 60 & 10 & 10 & 0.6 \\
\hline & Dot preservation & Yes & Yes & Yes & No \\
\hline & Corresponding figure no. & $1(\mathrm{a})$ & 1(b) & 2(a) & 2(b) and (c) \\
\hline
\end{tabular}

\subsection{SEM analysis}

SEM observations were performed on a JEOL JSM-6700F. The energy of the primary electron beam was varied from 3 to $15 \mathrm{kV}$ to play on the transparency of the sample components. Backscattering contrast between the graphitic layers (low $Z$ ) of the nanotubes and the metallic particles (high $Z$ ) emphasized the presence of metal. Most of the images were recorded with a 'through the lens' secondary electron detector (SEI). The distances directly measured on the pictures had to be corrected taking into account the tilt angle $\theta$ between the substrate and the plane normal to the electron beam. The real length $L_{\mathrm{r}}$ of 


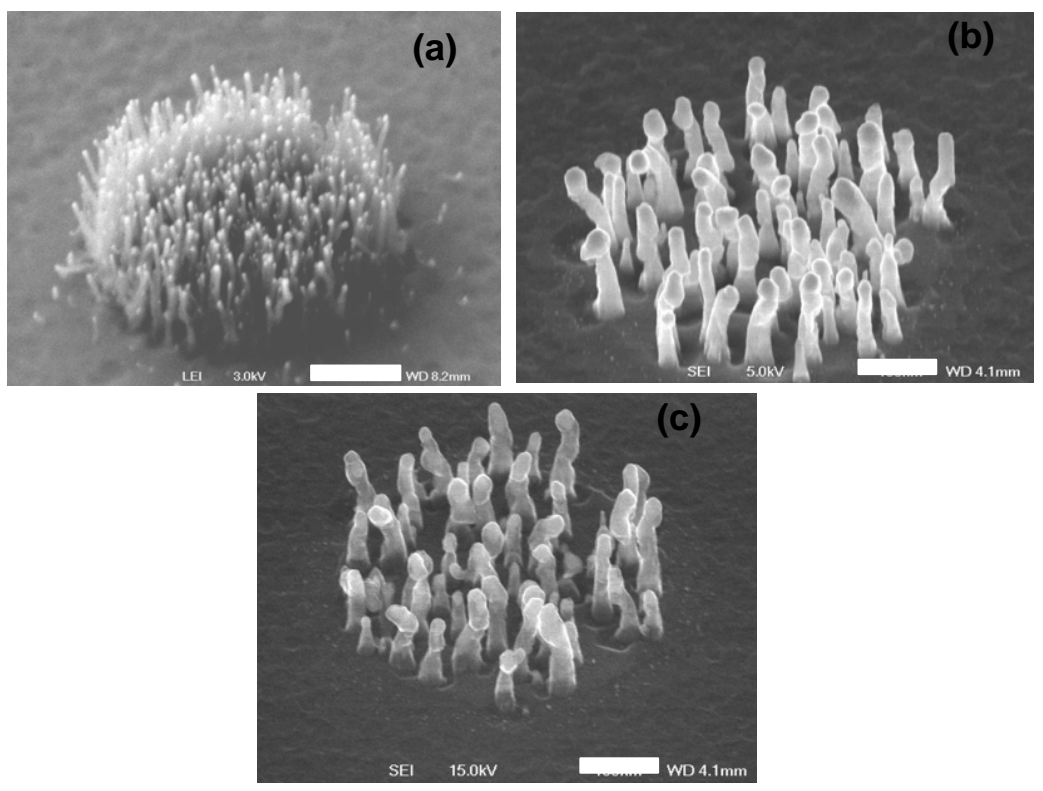

Figure 1. SEM micrographs of MWNTs grown on micron-sized metal dots obtained after UV lithography. The supported-catalyst metal is iron for (a) and nickel for (b) and (c). The observations were carried out with an incident electron beam of $3 \mathrm{kV}$ ((a) and (b)) and $15 \mathrm{kV}$ (c) and a tilt angle of $45^{\circ}$. The scale bar length is $400 \mathrm{~nm}$ for the three micrographs.

a MWNT was calculated from the distances directly measured $L_{\mathrm{m}}$ on the micrographs as follows: $L_{\mathrm{r}}=L_{\mathrm{m}} / \cos (90-\theta)$.

The density was merely calculated by dividing the number of nanotubes by the area of the dot and the growth rate was the mean MWNT length divided by the growth time, assuming a constant growth rate. The obtained mean values of diameters, lengths and densities have been reported in the third part of table 1 .

\section{Results and discussion}

\subsection{Experimental conditions for the growth of individual MWNTs}

Scheme 1 illustrates the lithographic sequences carried out to obtain isolated, localized and oriented MWNTs. The control of the final dot size is achieved by means of the successive topdown lithography steps detailed in the previous part. Steps 4, 5 and 6 are illustrated with SEM micrographs. The experimental conditions during the synthesis, for instance gas mixture and dot size range, were determined subsequent to results obtained for nanotubes directly grown on the initial micron-sized UVlithographied dots, i.e. immediately after step 4 in scheme 1 . We have investigated either nickel or iron as the catalytic support. We focused on the comparison of their behavior during the DC HF CCVD process, especially regarding the breaking up of the initial dot and surface diffusion phenomena of the metallic particles created.

3.1.1. Catalyst structuring and MWNT growth mechanism. Figure 1 is a SEM micrograph of MWNTs catalyzed by iron (figure 1(a), sample A) and nickel (figures 1(b) and (c), sample B) on micron-sized dots of about the same initial size. Aligned MWNTs were grown on the whole dot area. Most of the experimental conditions remained unchanged during the growth process (cf section 2.2 and table 1). There are, however, significant differences between the diameters and the densities of MWNTs catalyzed by the two catalysts. Iron favors the formation of MWNTs having a diameter much thinner than nickel. The third part of table 1 gives a statistical analysis of the characteristics of the nanotubes in both cases. The MWNT mean diameter of sample A is around $20 \mathrm{~nm}$, whereas in the case of nickel the diameter is around $84 \mathrm{~nm}$. Moreover, in the iron case, the mean density of MWNTs is much higher, by a factor of 6 , than for the nickel dots. During the first step of the CVD process, the substrate is annealed under $\mathrm{H}_{2}$ up to $700{ }^{\circ} \mathrm{C}$. The metal film which is deposited at room temperature using $\mathrm{MBE}$ is homogeneous and localized on the micron-sized dot area. It is well known that the increase of temperature induces a splitting up of a metal film into nanosized particles due to the non-wetting of the metal on the silicon oxide surface and to different thermal expansion coefficients between the metal and the substrate. It has been shown that, under the same annealing conditions, the mean size of these nanoparticles depends on the quantity deposited [23] and on the energy of interaction between the metal and the substrate. The unchanged total size of the micronic dot before (SEM micrograph at step 4, scheme 1) and after the CVD process (figure 1) guarantees a very weak diffusion of metal catalyst on the substrate surface. The metal is confined in the dot area and breaks up to form nanoparticles from which the nanotubes grow up. Carbon coming from the decomposed gaseous species diffuses from the particle surface across the metal. Then carbon segregates on the opposite side by forming graphite sheets oriented perpendicularly to the substrate [24]. Each particle consequently catalyzes one MWNT, of which the morphological characteristics depend on those of the initial nanoparticles. The high density and the small diameter 

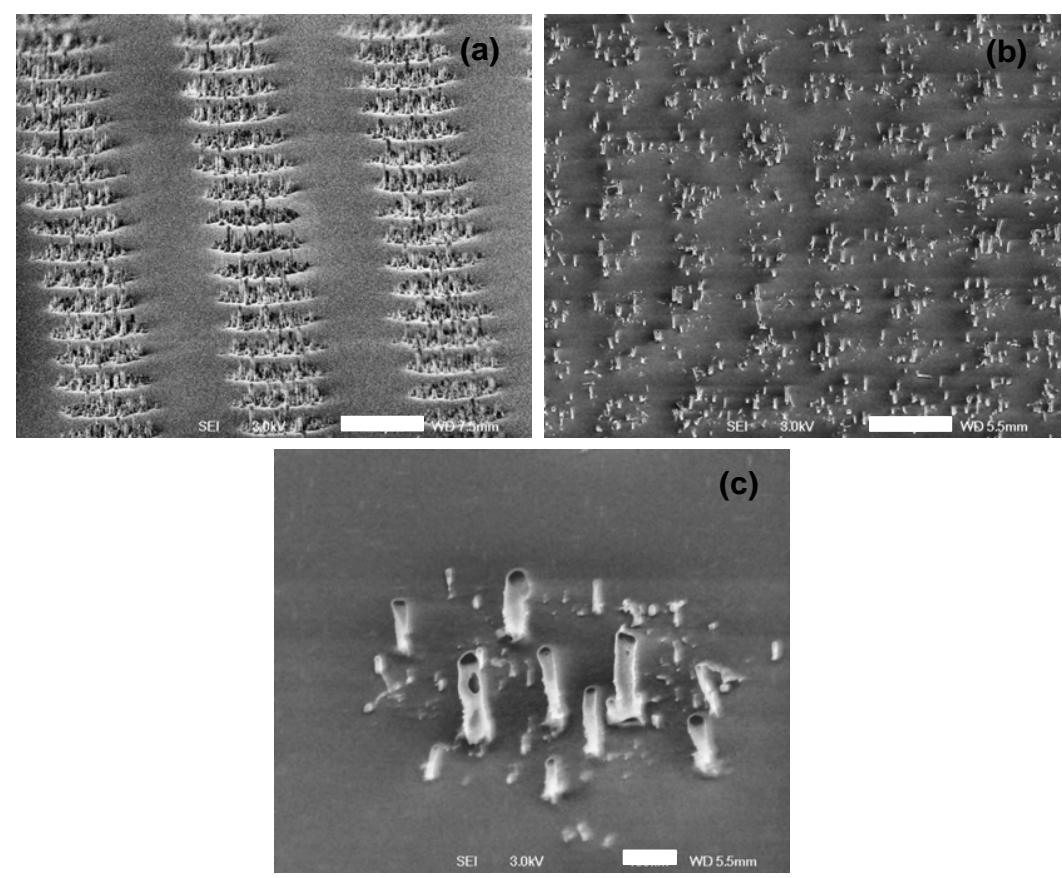

Figure 2. SEM micrographs of MWNTs grown on a nickel dot obtained by UV lithography after a synthesis process varying the ammonia concentration in the gas mixture. MWNTs of (a) (the scale bar length is $2 \mu \mathrm{m}$ ) have been synthesized with $1 \% \mathrm{NH}_{3}$. (b) (The scale bar length is $4 \mu \mathrm{m}$ ) and (c) (the scale bar length is $600 \mathrm{~nm}$ ) are micrographs of samples obtained increasing the ammonia concentration up to $3 \%$ and taken with low and high magnifications, respectively. The observation tilt angle is $82^{\circ}$ for (a) and $45^{\circ}$ for (b) and (c).

observed for MWNTs synthesized from iron show that iron has a high tendency to break up compared to nickel. Nickel, which has a weaker interaction with $\mathrm{SiO}_{2}$, favors the formation of larger catalytic particles and consequently it catalyzes MWNTs having much larger diameters.

Moreover, for sample A (figure 1(a)), the top end of the nanotubes comes out whitish by comparison with their graphitic walls. This supports the presence of iron nanoparticles laid at the top of the nanotubes (cf section 2.3). In the nickel case, the existence of the metallic particle on top of the nanotubes has also been revealed by increasing the energy of the primary electron beam up to $15 \mathrm{kV}$ (figure 1 (c)) for the SEM observations. Carbon nanotube shells becoming transparent, one can distinguish the whitish nickel nanoparticle more or less stretched inside the nanotubes [25]. These observations are the signature of MWNTs formed by a topgrowth mechanism [8]. This latter, rather than the basegrowth mechanism, is usually observed in CVD processes as soon as catalytic metal was deposited using a weak energetic deposition technique such as MBE used in this work. Then the impinging metallic atom does not strongly interact with the substrate, and the catalytic particle can be lifted off in the course of the CNT growth. By contrast, the high energy metallic ions used in deposition techniques like magnetron sputtering or ion implantation [26] are partly shallow implanted into the substrate, giving rise to a strong adhesion of the metallic layer to the substrate and a basegrowth mechanism is observed.

3.1.2. Ammonia influence on surface diffusion/etching. We have investigated the effect of ammonia on the catalyst structuring. Samples B, C and D were prepared with 0,1 and $3 \%$ of $\mathrm{NH}_{3}$ added to the reactant mixture, respectively, and with nickel as catalyst. Figure 2 displays MWNTs grown on micron-sized nickel dots with two different gaseous mixture conditions. Figure 2(a) is a SEM micrograph of sample C prepared with $1 \%$ ammonia added to hydrogen used as the gas vector. The gaseous mixture is, in that case, composed of $20 \% \mathrm{C}_{2} \mathrm{H}_{2}$ and $1 \%$ of $\mathrm{NH}_{3}$ diluted in $\mathrm{H}_{2}$. Micrographs in figures 2(b) and (c) are low and high magnifications, respectively, for a synthesis process performed with 3\% of ammonia (sample D).

No evolution of the area of the initial dot is observed with $0 \% \mathrm{NH}_{3}$ (not shown) and $1 \% \mathrm{NH}_{3}$ concentrations. Although the global area of the initial dots was preserved for sample $\mathrm{C}$ (figure 2(b)), increasing the concentration of $\mathrm{NH}_{3}$ up to $3 \%$ amplifies drastically the diffusion of nickel onto the $\mathrm{SiO}_{2}$ surface. Nickel is now spread out of the initial dot area and it catalyzes MWNT growth even on areas that were not previously covered by metal. Catalytic patterning is completely destroyed by the ammonia engraving. Ammonia, usually used to inhibit the competing amorphous carbon formation, favors then the splitting up and the diffusion of metal on the $\mathrm{SiO}_{2}$ surface. Increasing, as well, the accessibility of gaseous carbon species at the surface of metal particles [27], the addition of $\mathrm{NH}_{3}$ leads to a significant augmentation of the MWNT growth rate, starting from $17 \mathrm{~nm} \mathrm{~min}^{-1}$ without ammonia up to $45 \mathrm{~nm} \mathrm{~min}^{-1}$ for $3 \%$ of ammonia.

3.1.3. Choice of experimental conditions and dot size range. The third part of table 1 summarizes the comparative analysis regarding the characteristics of MWNTs grown on micronsized dots as a function of the catalytic metal and the ammonia 

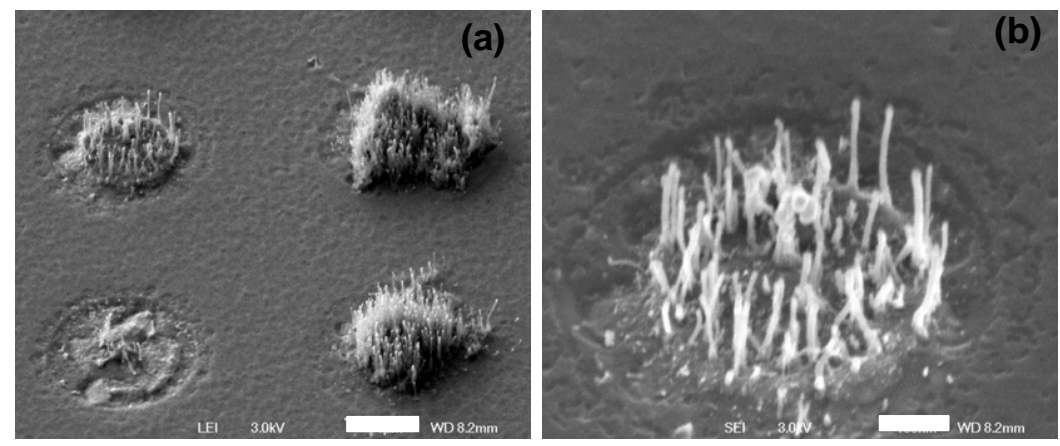

Figure 3. SEM micrographs of MWNTs grown on iron micron-sized dots which have been previously etched using the FIB technique. (a) This shows four dots: going from the right bottom to the left bottom counterclockwise, the exposure time is $5 \mathrm{~s}, 10 \mathrm{~s}, 20 \mathrm{~s}$ and $30 \mathrm{~s}$, respectively, the internal diameter of the FIB etching beam being fixed at $140 \mathrm{~nm}$. The scale bar length is $1 \mu \mathrm{m}$. (b) This is a dot engraved during $20 \mathrm{~s}$ observed at higher magnification. The scale bar length is $200 \mathrm{~nm}$.

concentration during the CVD process, the other experimental conditions remaining unchanged. As we have seen for sample $\mathrm{D}$, the addition of $\mathrm{NH}_{3}$ in the gaseous mixture strongly increases the MWNT growth rate [28], but also modifies the micron-sized dot shape (at high $\mathrm{NH}_{3}$ content), the density but also the quality of the nanotubes. Thus, accounting for all these parameters a good compromise would be to use $0.5 \% \mathrm{NH}_{3}$ [29]. Even if a high growth rate is generally an advantage for a synthesis process, the non-preservation of the initial metallic dot is here clearly inadequate for further investigations. In our case, it is necessary to precisely control the morphology and the location of metal particles. This is the reason why the synthesis is further carried out without any addition of ammonia during the CVD process.

The discrimination between iron and nickel as catalysts is not obvious regarding the results obtained on micron-sized dots. The growth rate is not significantly changed for both catalysts (samples A and B). The main difference between iron and nickel stands on their ability to split up, leading to the formation of dense and thin MWNTs in the iron case and to MWNTs having a much lower density and a higher diameter when nickel is used. Based on these results, both catalysts have been investigated to prepare nanosized particles to grow one individual MWNT per dot. UV lithography is then followed by the FIB lithography technique according to step 5 in scheme 1 in order to achieve a metallic dot size within the $20-240 \mathrm{~nm}$ range.

\subsection{Synthesis of individual and oriented MWNTs}

3.2.1. The case of iron. SEM micrographs in figure 3 show MWNTs catalyzed by iron dots prepared using the optimized FIB procedure which have been previously described in part 2.1 (scheme 1, step 5). Surprisingly, we have not observed any significant difference by varying the dot diameter from 20 to $240 \mathrm{~nm}$. A representative behavior (for a FIB beam size of $140 \mathrm{~nm}$ ) is shown in figure 3(a) while the exposure time of the ionic etching stage varies from 5 to $30 \mathrm{~s}$.

Starting from the bottom right dot and going counterclockwise, the exposure time is $5 \mathrm{~s}, 10 \mathrm{~s}, 20 \mathrm{~s}$ and $30 \mathrm{~s}$, respectively. For the weakest times (5 and $10 \mathrm{~s}$ ), the dots appear deformed from their initial disc shape. Iron has probably been sputtered by gallium ions out of the former UV-lithographed dot, as revealed by the occurrence of MWNTs grown onto a more extended area than the one of the former dot. This is especially noticeable on the upper right dot. For highest exposure times, there is no more evidence of iron diffusion but the prolonged ion beam exposure radically reduces the MWNT density.

Figure 3(b) is a high magnification SEM picture of the FIB-treated dot during $20 \mathrm{~s}$. MWNT growth is favored on the former UV-dot border. On the one hand, the ion beam dose is not strong enough to entirely remove the iron, but on the other hand, this dose is capable of digging into the substrate, as can be seen all around the UV-dot. It is assumed that the efficiency of the ionic engraving is limited because of the extreme ability of iron to split up, as we have previously discussed. The ion beam, hitting the dots, ejects atoms from the metallic surface which are falling down all along the exposure stage and deposit at the end on the perimeter of the initial micronsized dot, which represents a preferential adhesion zone. On the perimeter, the initial micron-sized metallic dot forms a step with the substrate which is improved by the $\mathrm{Ga}^{+}$etching. Thus it is believed that iron particles diffusing at the surface will be preferentially trapped at the edge of this step. In addition, a deformed MWNT has grown up at the center of the dot, exactly at the location where the $140 \mathrm{~nm}$ dot should have been formed. This unconventional growth is probably a consequence of the presence of $\mathrm{Ga}^{+}$ions making a stable alloy with $\mathrm{Fe}$ which affects the catalytic power of iron. Moreover, the probability to agglomerate for etched iron atoms isotropically diffusing onto the surface is maximum at the center of the initial dot.

Except for the deformed MWNTs which have developed at the center of dots etched with intermediate exposure times, MWNTs grown after the FIB lithography have slightly the same characteristics, diameter and density than those synthesized on the UV-lithographed dots. Their diameter remains around $25 \mathrm{~nm}$ and the growth rate of $31 \mathrm{~nm} \mathrm{~min}^{-1}$ is almost unaffected. This is a good indication that $\mathrm{Ga}^{+}$ ions at low doses do not affect the catalytic activity of iron. Nevertheless, because of the high tendency of iron to break up, it turns out that the FIB technique is inappropriate for the reduction of the size of the former UV-prepared dots in order to grow a localized and unique MWNT. 


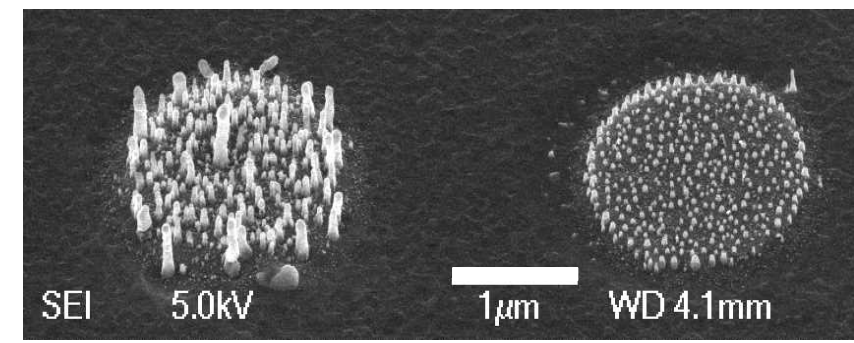

Figure 4. SEM micrographs illustrating the representative results of the effect of the exposure time during the FIB treatment onto micron-sized nickel dots. On the left side, the dot is etched with an exposure time of $5 \mathrm{~s}$ and for a diameter fixed at $240 \mathrm{~nm}$. For the right dot, the exposure time is increased to $20 \mathrm{~s}$ for a diameter fixed at $20 \mathrm{~nm}$.

3.2.2. The case of nickel. Figures 4 and 5 display SEM micrographs of carbon nanotubes grown on nanosized dots of nickel prepared by UV lithography and followed by size reduction using FIB etching. Figure 4 shows two nanosized dots resulting from ionic etching for extreme conditions.
The left one is etched for $5 \mathrm{~s}$ and for a diameter of $240 \mathrm{~nm}$ and the right one corresponds to an exposure time of $20 \mathrm{~s}$ and a diameter of $20 \mathrm{~nm}$. As for the iron case, $5 \mathrm{~s}$ is not long enough to efficiently remove the metal. Even if the growth irregularly occurs on the entire area of the former micron-sized dot, one single nanotube stands at the center. Again, the growth is rather favored along the external perimeter of the micron-sized dot. Increasing the exposure time up to $20 \mathrm{~s}$, nickel has now been efficiently removed. In the case of a diameter of $20 \mathrm{~nm}$, MWNT growth is, however, totally inhibited. White objects, a kind of 'buds', with a diameter around several tens of nanometers cover the micronsized initial dot surface. Rarely, MWNTs still grow out of the dots, probably from nickel nanoparticles expelled by the ion beam. Former UV-lithographed dots are noticeable on the darker clean and smooth $\mathrm{SiO}_{2}$ surface.

Working with an exposure time of $20 \mathrm{~s}$ and varying the internal diameter of the etching pattern, typical results after CNT growth are shown in figure 5. Following the lines, from left to right, the diameter of the nanosized dots was varied as follows: 20, 40, $60 \mathrm{~nm}$ for the first line, 80, 120, $160 \mathrm{~nm}$ for the second one, and finally 200, $240 \mathrm{~nm}$ for the third one. MWNTs
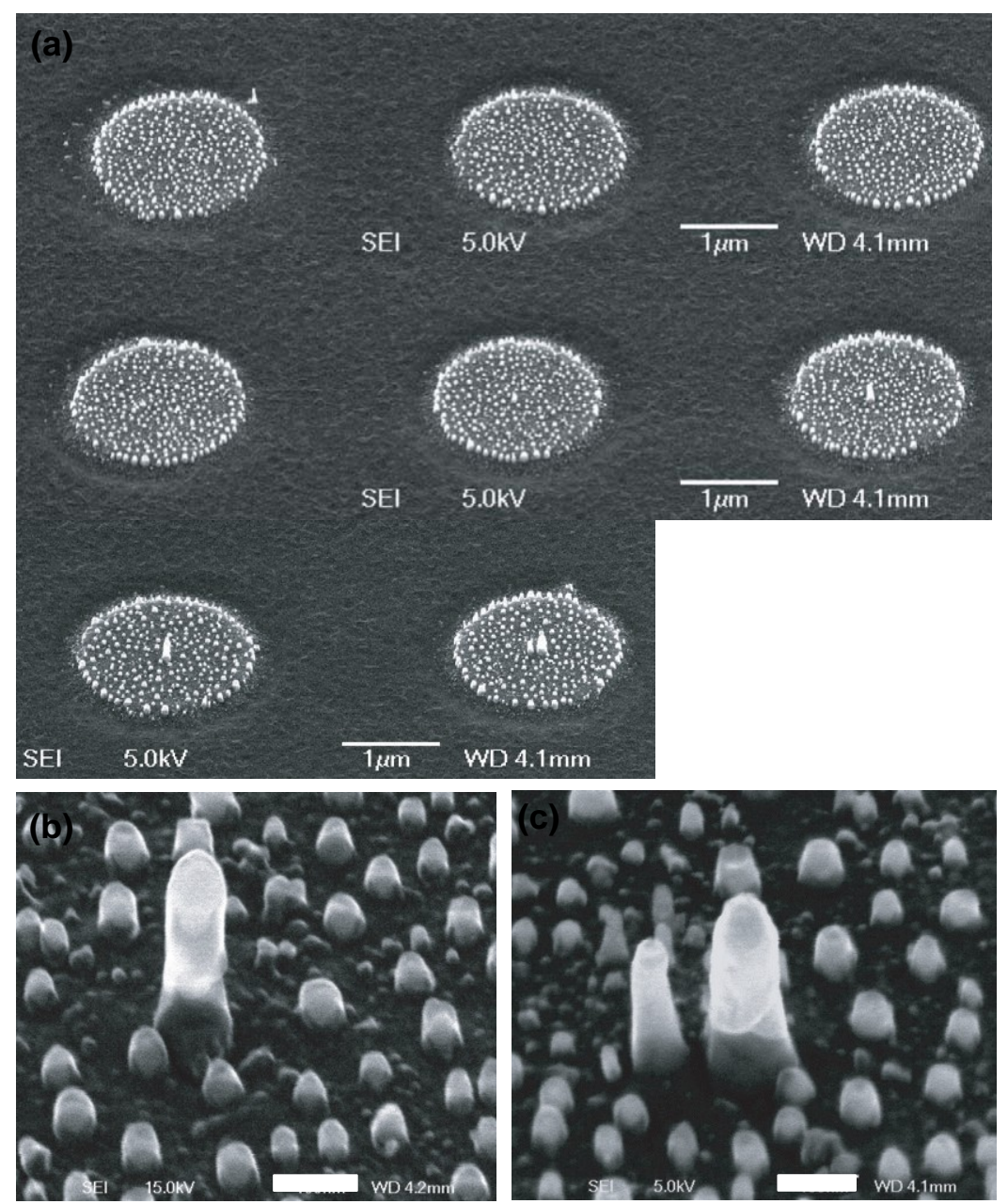

Figure 5. SEM micrographs of CNT grown after initial dot reduction using the FIB technique, varying the internal diameters with a fixed exposure time of $20 \mathrm{~s}$. (a) Following the lines from left to right the internal diameters are 20, 40, 60, 80, 120, 160, $200 \mathrm{and} 240 \mathrm{~nm}$. (b) SEM micrograph of a single MWNT grown on the $200 \mathrm{~nm}$ diameter dot and taken at a primary electron flux of $15 \mathrm{kV}$. (c) SEM micrograph of the 'twins' grown onto the $240 \mathrm{~nm}$ diameter dot and observed with a primary electron beam of $5 \mathrm{kV}$. 
do not grow on dots which have a diameter smaller than $120 \mathrm{~nm}$ and, for this precise diameter, a bud bigger than the other ones rather than a real carbon nanotube is starting to grow up at the center of the dot. The increase of the nickel dot at diameters above $120 \mathrm{~nm}$ makes possible the synthesis of MWNTs. For diameters in between 160 and $240 \mathrm{~nm}$, one single nanotube is generally obtained. $240 \mathrm{~nm}$ is the upper limit to obtain one isolated nanotube, twin MWNTs are then observed, as shown in figure 5(c). Figure 5(b) is a high magnification micrograph of one typical individual MWNT observed with a high energy of the primary electron beam. Here again, the MWNT is capped with a nickel nanoparticle at the top, playing with the transparency of metal and carbon. As we previously discussed, this is again evidence of a top-growth mechanism. It is important to note that the previous FIB etching treatment has not modified the weak adhesion of the metallic particle with the surface, as would be expected if some $\mathrm{Ga}^{+}$ions had induced the incorporation of some Fe atoms into the shallow surface of the substrate through collisions.

As in the iron case, there is no significant difference between the sizes of carbon nanotubes catalyzed by nickel before and after the FIB treatment. In contrast, the growth rate decreases by a factor of $30 \%$ due to the ion beam etching. It was quoted as $17 \mathrm{~nm} \mathrm{~min}{ }^{-1}$ without FIB treatment and around $12.5 \mathrm{~nm} \mathrm{~min}{ }^{-1}$ on the smaller dots. In addition, considering these non-conventional objects, such as buds and deformed tubes observed on the metal-etched zone, $\mathrm{Ga}^{+}$ions do not simply engrave the metal but also are redeposited on the substrate surface. The catalytic power of the metal is then modified and leads to the decrease of the growth rate in the case of nickel. In contrast, iron, having a high ability to split up and probably a higher mobility on the surface, shows a growth rate almost unchanged after the FIB lithography step (27 and $31 \mathrm{~nm} \mathrm{~min}{ }^{-1}$ before and after the FIB treatment, respectively).

In the case of nickel, we have shown that one single nanotube per dot is obtained for dot diameters of $200 \pm 40 \mathrm{~nm}$.

Such a submicronic dot size range is quite accessible using electron top-down lithography. The procedure is exactly the same as the UV lithography one, but in that case, the polymer must be electron-sensitive and the dots formed after the development (cf step 4, scheme 1) have directly a diameter down to $50 \mathrm{~nm}$ for the best case. Results obtained by this process have shown that one single nanotube per dot is grown from a dot size with a diameter of $100 \mathrm{~nm}$ [30, 31]. This value is in good agreement but slightly smaller than the one determined in this study. The small discrepancy could be explained by catalytic inhibition of the dot surface by gallium ions.

\section{Conclusion}

Micron-sized metallic dots were first obtained using classical UV lithography on $\mathrm{SiO}_{2}(10 \mathrm{~nm}) / \mathrm{Si}(100)$ substrates. The patterned substrates were used for the growth of MWNTs. The synthesis is carried out in a home-developed DC HF CCVD reactor. The nature of the catalytic metal ( $\mathrm{Ni}$ or $\mathrm{Fe}$ ) and the experimental conditions of the CVD process are studied. An increasing ammonia concentration up to $3 \%$ leads to surface diffusion of the metal particles out of the initial dots. Ni dots are less broken up than Fe dots. These results are used in the second part of this work where a reduction of the initial dot to nanometric sizes is achieved in order to grow one single MWNT per dot. The FIB etching was used to control the metal dot size down to $20 \mathrm{~nm}$. Preparing, in this way, nickel particles within the $200 \pm 40 \mathrm{~nm}$ range, we succeed in the growth of individual and oriented MWNTs. It is verified that $\mathrm{Ga}^{+}$ions during the FIB process do not alter Fe or slightly alter the catalytic activity for MWCNT growth.

It turns out that the nature of the catalytic metal plays an important role in the growth rate and the morphology of the carbon nanotubes because of the interaction forces with the oxide substrate during the CVD process, conditioning both the effect of ion beam etching and the ability of the thin metallic film to split up. Even if the lithographic procedure we have investigated needs several steps to obtain nanometer-sized dots, it offers the required accuracy to control the dot size in the nanometer scale and one single carbon nanotube at a precise location on a substrate.

In addition, working on lithographed substrates reduces the carbon nanotube density and increases consequently the quality of the observations. Fine SEM analysis notably allows us to prove that MWNTs were formed from a top-growth mechanism due to weak adhesive forces between the metal and $\mathrm{SiO}_{2}$ surface, even after an FIB etching treatment. The final nanometer-sized dots (or particles) prepared by ion beam etching are separated from each other by several microns on the surface. This distance prevents the metal atoms to diffuse from one particle to another. Complex sintering phenomena, such as Oswald ripening, occurring when a metal deposited on an oxide substrate is further annealed at high temperature, are here forbidden. Such catalytic metal preparation can obviously have some interest for the understanding of the MWNT synthesis, especially regarding the structuring of metal during the CVD process and the growth mechanisms.

\section{Acknowledgments}

The authors acknowledge the French Research Ministry though the RMNT 'CANAST' project for financial support and thank A Carvalho for useful help and discussion. They also acknowledge $\mathrm{T}$ W Ebbessen for access to the FIB apparatus at ISIS, Strasbourg.

\section{References}

[1] Saito R, Dresselhaus G and Dresselhaus M S 1998 Physical Properties of Carbon Nanotubes (London: Imperial College Press)

[2] Collins P G, Zettl A, Bando H, Thess A and Smalley R E 1999 Science 2862148

[3] Purcell S T, Vincent P, Journet C and Thien Binh V 2002 Phys. Rev. Lett. 88105502

[4] Dai H, Franklin N and Han J 1998 Appl. Phys. Lett. 731508

[5] Kim P and Lieber C M 1999 Science 2862148

[6] Hofmann S, Cantoro M, Kaempgen M, Kang D J, Golovko V B, Li H W, Yang Z, Geng J, Huck W T S, Johnson B F G, Roth S and Robertson J 2005 Appl. Phys. A 811559

[7] Thelander C and Samuelson L 2002 Nanotechnology 13108

[8] Baker R T K 1989 Carbon 27315 
[9] Willems I, Konya Z, Colomer J-F, Van Tenderloo G, Nagaraju N, Fonseca A and Nagy J B 2000 Chem. Phys. Lett. 31771

[10] Lee C J and Park J 2001 J. Phys. Chem. B 1052365

[11] Kim N S, Lee Y T, Park J H, Ryu H, Lee H J, Choo J and Choi S Y 2002 J. Phys. Chem. B 1069286

[12] Wong M S, Cheng K-W, Shee C-H, Ma Y-R, Wu J C, Liou Y and Yao Y-D 2004 J. Appl. Phys. 957291

[13] Ren Z F, Huang Z P, Xu J W, Wang J H, Bush P, Siegal M P and Provencio P N 1998 Science 2821105

[14] Bower C, Zhou O, Zhu W, Werder D J and Jin S 2000 Appl. Phys. Lett. 772767

[15] Choi Y C, Shin Y M, Lee Y H, Lee B S, Park G-S, Choi W B, Lee N S and Kim J M 2000 Appl. Phys. Lett. 762367

[16] Cojocaru C S, Kim D, Pribat D and Bourée J-E 2006 Thin Solid Films 501227

[17] Lei T, Yeong K-S and Thong J T L 2004 Chem. Mater. 162757

[18] Yap H Y, Ramaker B, Sumant A V and Carpick R W 2006 Diamond Relat. Mater. 151622

[19] Le Normand F, Cojocaru C S, Fleaca C, Li J Q, Vincent P, Pirio G, Gangloff L, Nedellec Y and Legagneux P 2007 Eur. Phys. J. Appl. Phys. 38115

[20] Cojocaru C S, Larijani M, Misra D S, Singh M K, Veis P and Le Normand F 2004 Diamond Relat. Mater. 13270
[21] Cojocaru C S, Senger A and Le Normand F 2006 J. Nanosci. Nanotechnol. 61331

[22] Cojocaru C S and Le Normand F 2006 Thin Solid Film 51553

[23] Chhowalla M, Teo K B, Ducati C, Rupesinghe N L, Amaratunga G A J, Ferrari A C, Roy D, Robertson J and Milne W I 2001 J. Appl. Phys. 905308

[24] Ducati C, Alexandrou I, Chhowalla M, Robertson J and Amaratunga G A J 2004 J. Appl. Phys. 956387

[25] Okai M, Muneyoshi T, Yaguchi T and Sasaki S 2000 Appl. Phys. Lett. 773468

[26] Louchev O A, Sato Y and Kanda H 2002 Appl. Phys. Lett. 802752

[27] Han J-H, Lee C H, Yang C W, Yoo J B, Park C Y, Kim H J, Jung D Y, Park G S, Yi W, Han I T, Yu S G, Lee N S and Kim J M 2002 Thin Solid Film 409120

[28] Mane Mane J, Cojocaru C S, Barbier A, Deville J P, Thiodjio Sendja B and Le Normand F 2007 Phys. Status Solidi b 2044209

[29] Cojocaru C S and Le Normand F, unpublished results

[30] Teo K B K, Chhowalla M, Amaratunga G A J, Milne W I, Hasko D G, Pirio G, Legagneux P, Wyczisk F and Pribat D 2001 Appl. Phys. Lett. 791534

[31] Teo K B K, Chhowalla M, Amaratunga G A J, Milne W I, Hasko D G, Pirio G, Legagneux P, Wyczsik F and Pribat D 2003 Nanotechnology 14204 